\title{
APUNTACIONES PARA LA HISTORIA DEL DERECHO PERUANO. UN CASO DE POLÍTICA ASISTENCIAL EN FAVOR DE LOS PARTIDOS DEL CORREGIMIENTO DE HUAYLAS EN EL S. XVIII
}

\author{
MANUEl ENRIQUE VALVERDE GONZÁLES*
}

\begin{abstract}
Resumen
Se ofrece una retrospectiva histórica de los movimientos sociales indígenas surgidos en el siglo XVIII en el denominado Corregimiento de Huaylas, en el marco de las reformas introducidas en la estructura hacendaria por la administración colonial, destinadas a obtener mayor recaudación de caudales para la corona española, y de los excesos cometidos por la burocracia intermediaria encargada de la rigurosa recaudación de los tributos; hechos bajo cuyo contexto se analizan las repercuciones jurídicas del expediente promovido por los curacas de la doctrina de la provincia de Huaylas ante la administración política del Virreynato del Perú, con el objeto de lograr el auxilio económico con los fondos de la Caja de Censos del Corregimiento, a fin de que se socorra a los indios de dicha provincia.
\end{abstract}

Palabras clave: Administración colonial - Real Hacienda - Corregimiento Tributación indígena - Censo fiscal - Exacciones - Insurrección - Legislación indiana - Auxilio económico a los indígenas.

\begin{abstract}
A historical retrospective of the social indigenous movements in the 18th Century in the County of Huaylas, within the context of tax reforms introduced by the colonial administration with the aim of obtaining greater revenues for the Spanish crown, and the abuses committed by the intermediary bureaucracy in charge of tax collection. This article analyzes the legal repercussions of the action promoted by the leaders of the doctrine of the County of Huaylas before the political administration of the Viceroyalty of Peru with the aim of obtaining financial aid from the funds of the Census Bank of the County, to assist the indigenous peoples of said Province.
\end{abstract}

Key words: Colonial Administration - Royal Tax Office - County - Indigenous Taxation - Tax Census - Tax Levying - Insurrection - Indian Legislation Economic aid for the natives.

\section{Sumario}

1. Preliminares. 2. Revueltas indígenas. 2.1. La revuelta de Caráz. 2.2. Revuelta de las acabalas. 3. Del Corregidor Marqués de Casa Hermosa. 4. La petición de auxilio de los tributarios. 5. Expresión jurídica. 6. Colofón.

\footnotetext{
* Asesor de la Presidencia del Poder Judicial del Perú.
} 
Manuel Enrique Valverde Gonzáles - Apuntaciones para la historia del derecho peruano. Un caso de política asistencial en favor de los partidos del corregimiento de Huaylas en el S. XVIII

\section{PRELIMINARES}

Al tomar los borbones las riendas de España en los albores del siglo dieciochesco, emprendieron la labor de encontrar las mejores formas para optimizar la administración colonial en América, buscando la manera de hacerla más dinámica y moderna, tendiendo a una, cada vez mayor, recaudación de caudales hacia las arcas reales, las que a su vez, cerrando el círculo vicioso de derroche, discurrían en mantener la nobleza parasitaria de la Corte ibérica.

La recaudación tributaria, desde inicios, tuvo incidencia importante en la política fiscal colonial, pues ésta llegaba a ser la columna vertebral de toda la estructura hacendaria de la corona, que se manifestaba de diversas formas: tributo, quinto real, almojarifazgos, alcabalas, seguidos de los diezmos y primicias, por solamente citar los más importantes.

Dicha recaudación recayó, desde siempre, sobre el estrato más pobre y bajo del Estado colonial que estaba constituido por los indígenas, y se realizaba mediante una intrincada burocracia intermediaria, la que estaba encarnada por el corregidor, el encomendero y los curacas. Estos últimos no tenían ningún tipo de contemplaciones para con sus hermanos de raza en el cobro excesivo de los tributos.

Por el año de 1501, con las instrucciones del Gobernador Obando, se establece la idea del tributo con caracteres fiscales, hecho que se mantiene a lo largo de toda la etapa virreinal americana, razón por la cual se cobraba rigurosamente a todos los regnícolas.

En 1553 se llegó a dictar una Real Cédula, por medio de la cual se ordenaba, que al momento de hacer la tasación, se tomara en cuenta las exacciones que recayeran sobre los indígenas, de tal modo que el tributo no los agobiara.

Sabido es que estas leyes solamente eran meras declaraciones de buenas intenciones que no tenían un correlato con la realidad, pues en la práctica se evidenciaban los excesos cometidos contra los indígenas por los funcionarios de consuno con los curacas, sumándose a ellos muchos clérigos doctrineros. Ello motivaba que los indígenas se mostraran estar más dispuestos a pagar el tributo que las cargas eclesiásticas, provocando la competencia entre curas y corregidores. A esto hay que agregar que la aparición de los corregidores, trajo como consecuencia el que los curacas se vieran reducidos a desempeñar las funciones de meros colectores con arreglo a los padrones o registros 
Manuel Enrique Valverde Gonzáles - Apuntaciones para la historia del derecho peruano. Un caso de política asistencial en favor de los partidos del corregimiento de Huaylas en el S. XVIII

hechos por estos nuevos funcionarios; descontento que no duró mucho, pues pronto lograron coludirse de perfecta manera; de modo tal que, como dice el notable historiador Guillermo Lohmann Villena, los corregidores manejaban dos padrones, el oficial y el propio, que independientemente o en connivencia con los curacas, contenía el censo real de los tributarios. No es menester especificar que el padrón o censo fiscal registraba un número inferior de contribuyentes que la nómina del corregidor ${ }^{1}$.

En lo que respecta a la labor de recaudación, el sistema usado por los corregidores fue el del arriendo de esta función a ciertos rematistas, que ofrecían una cantidad determinada por repartimiento; de esa forma, se pensaba, según lo sostiene el doctor Lohmann Villena, que no se coludirían tan fácilmente, por su propio interés, con los corregidores o curacas para declarar excedentes o fugitivos a los contribuyentes indígenas ${ }^{2}$.

La Recopilación de 1680 en su Ley 2, Título 5, Libro VI, establecía "que los indios reducidos y congregados a poblaciones paguen por dos años la mitad del tributo (...) y si fuesen infieles, la parte que se había de aplicar para la doctrina, se paga en caja separada para formar los hospitales en beneficio de los mismos indios y enviarles doctrina" 3 .

Hecho este introito general sobre el sistema de tributación indígena, el cual nos sirve como recuadro para poder entender un tanto mejor el tema que se desarrollará a continuación, nos avocamos a analizar lo atinente a la mecánica legal que funcionaba para que un delimitado grupo de solicitantes regnícolas

1 Cf. Lohmann Villena, Guillermo. El Corregidor de Indios en el Perú bajo los Austrias. Madrid: Ediciones Cultura Hispánica, 1957, p. 268, y pp. 316-317 de la $2^{\mathrm{a}}$ ed. a cargo del Fondo Editorial de la PUCP, Lima, 2001.

2 Durante la segunda mitad del s. XVIII, fue legalizado el reparto que realizaba el corregidor, convirtiéndose en otro medio de explotación de la población indígena y mestiza, a través de un sistema de deudas que permitía conseguir el pago en trabajo y en especie. En la década de los años setenta, la producción y el comercio fueron fuertemente gravados, incrementándose así las presiones tributarias sobre la población colonial. Como resultado de las mencionadas reformas borbónicas, la alcabala fue elevada hasta por dos veces en un período de cuatro años y se gravaron productos que antes estaban exentos. Sólo en diezmos y cobos de 993779.3 ps. que recolectaban en 1773-1776, se incrementó a 1' 213 642,1 ps. en 1777-1780; y en cuanto a tributos, de 913 327,1 ps. (en el primer período) aumentó a 1’609 576,7 ps. en 1777-1780.

LOHMANN. Op. cit., p. 274, y O'PHELAN, Scarlett. “Un siglo de Rebeliones Anticoloniales. Perú y Bolivia 17001783". Cusco: Centro Bartolomé de las Casas, 1988, p. 73.

3 Para mayores datos cabe agregar que en sus leyes xviii, xix y xx, se estipulaban las exenciones del pago del tributo por parte de los curacas y sus hijos, así como de las mujeres y de los alcaldes de indios.

Cf. Recopilación de leyes de los reynos de las indias (1681), t. 2, edición facsimilar, México, Escuela Libre de Derecho y M.A. Porrúa, 1987.

Resulta ilustrativo revisar los antecedentes de esta Recopilación realizada por Antonio León Pinelo, los mismos que han sido editados bajo el título: Recopilación de las Indias, en tres tomos, a cargo de la Escuela Libre de Derecho, Miguel A. Porrúa y otros, México, 1992, edición y estudio preliminar de Ismael Sánchez Bella. Para nuestro caso ver el t. II, pp. 1904 y ss. 
Manuel Enrique Valverde Gonzáles - Apuntaciones para la historia del derecho peruano. Un caso de política asistencial en favor de los partidos del corregimiento de Huaylas en el S. XVIII

pudieran obtener asistencia de los reales erarios coloniales frente a singulares situaciones que los apremiaban. Dicho esto, pasamos a la analizar el bagaje documental que hallamos en el Archivo General de la Nación (en adelante AGN), como producto de nuestras investigaciones realizadas respecto a la historia jurídica virreinal peruana.

En dicho repositorio ubicamos un legajo referente a los autos seguidos por los curacas del Corregimiento de Huaylas, conteniendo una petición dirigida a la administración política del virreinato del Perú con el objeto de lograr el auxilio económico con los rezagos de la Caja de Censos de su Corregimiento ${ }^{4}$.

En primer término, es importante hacer notar que, del análisis de los precitados autos, emerge de manera indubitable el estado de miseria en el que estaban sumidos los indígenas por una larga sequía existente y el azote de una epidemia de viruela que llegó a mermar notablemente la población del lugar, lo que hacía imposible el que los tributarios pudieran cumplir con sus obligaciones frente a la corona y al clero respectivamente ${ }^{5}$.

Además, como lo han sustentado muchos autores entendidos en el tema, entre ellos el P. Gridilla, para esta etapa finisecular ya se sentían los efectos del Tratado de Libre Comercio suscrito con Inglaterra y por tanto los artículos

\footnotetext{
4 Cf. AGN, Sección Derecho Indígena. Legajo 35, Cuaderno 715, Año 1780.

5 Según Jürgen Golte, la población indígena en la provincia de Huaylas era en 1754 aproximadamente de 20935 indios (51\% del total de la población), de los cuales 3857 eran tributarios, 3104 originarios y 753 forasteros. Por su lado el P. Soriano Infante nos comenta que en 1770 la provincia de Guaylas tenía: 44 curacas; 3104 originarios; 753 forasteros; 436 reservados; 2531 muchachos; 5673 mujeres; 12541 personas, 15 curas y contaba con 8584 pesos y 2 reales de sínodos.

Cf. GOLTE, Jürgen, Repartos y Rebeliones. Tupac Amaru II y las contradicciones de la economía colonial, Lima, IEP, 1980. Ver: cuadros Nº 9, p. 44 y N 13, p. 54; SORIANO INFANTE, A., "Corregidores de la provincia de Huaylas". En: Nueva Era. Revista inactual de Literatura, Crítica, Ciencia y Arte. Huaraz, Año III, No 7, diciembre, 1938, p. 1, (colección Manuel Reina Loli).

En una Revisita practicada en el Partido de Huaylas entre septiembre y mayo de 1785-1786, efectuada por el apoderado fiscal Manuel de Oyarzábal (siendo aún Subdelegado del Partido el Capitán de Milicias don Melchor Gutiérrez, dado que en noviembre de 1786 volvía a ocupar tal cargo el marqués de Casa Hermosa), se muestran los resultados de dicha labor, en la cual se informa que se dio inicio a tal retasa el 7 de septiembre de 1785, concluyendo el 30 de mayo de 1786, cuya recaudación corría a cargo de los curacas. Se indicaba la existencia de 5095 contribuyentes actuales en esos momentos, incluidos los ausentes; de los cuales 3221 eran originarios y forasteros con tierras, 1492 eran forasteros sin tierras y 370 mitmas, que cotejados con los 4082 de la última cuenta de 1782 (cuyo empadronamiento corrió a cargo del marqués de Casa Hermosa) había un aumento de 1013 tributarios. A mayores datos se detalla de manera pormenorizada que: 461 eran indios reservados por ser mayores de 40 años y otras enfermedades que les imposibilitaba tributar; 17 ausentes, cuyo paradero se desconocía; 156 próximos; 3768 muchachos; 8765 mujeres de todas las edades y estados.

Siendo así, excluidos los ausentes, quedaba reducido el número de personas de la "Nación índica" (síc. fs. 2v) del aludido Partido de Huaylas a 18280 personas que cotejadas con las 12945 de la anterior matrícula, se reconocía el aumento de 5335 indígenas $\left(^{*}\right)$. Puntualizándose luego que el número de contribuyentes útiles, exceptuados los reservados por edad e impedimento y los empleados al servicio de las iglesias de las doce doctrinas que componían dicho Partido era como sigue:
} 
Manuel Enrique Valverde Gonzáles - Apuntaciones para la historia del derecho peruano. Un caso de política asistencial en favor de los partidos del corregimiento de Huaylas en el S. XVIII

producidos en los obrajes y otros centros fabriles ya no tenían la acogida de la que habían gozado anteriormente y más bien estaban en franco retroceso en cuanto a su producción ${ }^{6}$.

\section{REVUELTAS INDÍGENAS}

Previamente a desarrollar el tema que nos convoca, no podemos dejar de lado algunos actos tumultuarios que se suscitaron por los años en que se formula el petitorio de los lugareños. En efecto, entre 1779 y 1780 ocurrieron

\begin{tabular}{|l|c|c|c|c|}
\hline Repartimientos & $\begin{array}{c}\text { Originarios y } \\
\text { forasteros con } \\
\text { tierras }\end{array}$ & $\begin{array}{c}\text { Forasteros sin } \\
\text { tierras }\end{array}$ & Mitmas & $\begin{array}{c}\text { Total } \\
\text { contribuyentes }\end{array}$ \\
\hline Guarás & 0092 & 0292 & 345 & 0689 \\
\hline Atunguailas & 2104 & 1109 & 172 & 3385 \\
\hline Choquerrequay & 0620 & 0086 & -- & 0706 \\
\hline Marca & 0247 & --- & --- & 0241 \\
\hline Cantidad & 3057 & 1447 & 517 & 5021 \\
\hline
\end{tabular}

Fuente: AGN Sección Tributos. Huaylas 1785-1786 (septiembre-mayo), Revisita del Partido de Huaylas. Leg. 3, c. 61 , fs. 2 y 3 .

Referente a las cantidades consignadas en el cuadro anterior, de los cuatro repartimientos, se corrobora la cifra total de 5021 tributarios útiles en un informe principal de la cuenta ordenada de tributos pertenecientes al año de 1787. Como ya se indicó era Subdelegado del Partido de Huaylas el Capitán Melchor Gutiérrez desde el 13 de noviembre de 1785 hasta noviembre de 1786, sucediéndolo en el cargo al marqués de Casa hermosa.

Cf. AGN Tributos, Intendencias. Leg. 3, c. 69, 1786-87, fs. 36.

En lo tocante a este personaje ver: Alba HeRrerA, Augusto, "Don Melchor Gutiérrez, primer benefactor de Caráz", en: Rev. Quiosco de Retretas. Bimensuario de carácter cultural, Caráz, año II, N 5, marzo-abril, 2003, p. 8; también su opúsculo: La sociedad de beneficencia pública de Caráz y sus benefactores, Caráz, Campus Films, 1996, p. 9-11 y 13-16.\}

$\left(^{*}\right)$ Es menester aclarar que la suma de los 3221 originarios, 1492 forasteros sin tierras y 370 mitmas da la cantidad de 5083 y no 5095 tributarios; el cotejo por tanto daría la diferencia de 1001 y no de 1013. En el segundo conteo la suma total, excluidos los 17 ausentes, da 13150 personas y no 18 280, ergo el cotejo final daría una diferencia de 205 individuos.

Para un mayor estudio de las causas que provocaban la fuga de los indígenas y su condición de ausentes y forasteros, ver EsCOBEDO MANSILLA, Ronald. El tributo indígena en el Perú (siglos XVI-XVII). Pamplona: Universidad de Navarra, 1979, pp. 78-90 y 156.

6 Cosme Bueno decía con respecto a la provincia de Huaylas que se criaba abundante ganado de cuyas lanas se fabricaba ropa de la tierra en varios obrajes que había en dicha provincia.

Por su parte el P. Gridilla, nos comenta que: "Las jergas y cordellates de Huaylas eran muy solicitados, y fue el gran negocio, hasta que declararon los reyes de España el comercio libre. Desde entonces se inició la decadencia hasta que, en el siglo XVIII, sobrevino la total ruina de aquella industria. Y lo que había en Huaylas y Conchucos, no eran simples chorrillos, sino verdaderos obrajes o fábricas de tejidos, en algunos de los cuales se empleaban centenares de personas, cuyos propietarios fueron indios en gran parte."

Precisamente, respecto a los obrajes, Fernando Silva-Santisteban refiere que en el s. XVIII, al aumentar el comercio lícito e ilícito con Europa, empezaron a decaer los obrajes americanos cuyos productos no podían competir con los extranjeros ni en calidad ni en baratura, pues procedían de elevada capacidad industrial. Las disposiciones que permitieron el comercio libre, la rebelión de 1780 y la política contraria a estas industrias terminaron con gran parte de los obrajes del Alto y Bajo Perú. Muchos obrajes presentaban el aspecto de grandes factorías, ya que en algunos trabajaban hasta cuatrocientos operarios, como en el obraje 
Manuel Enrique Valverde Gonzáles - Apuntaciones para la historia del derecho peruano. Un caso de política asistencial en favor de los partidos del corregimiento de Huaylas en el S. XVIII

una serie de revueltas a lo largo del corregimiento de Huaylas. Insurrecciones que fueron producto de la oprobiosa situación por la que atravesaban los pobladores indígenas, agudizada por la presencia del visitador Areche, que pasó a incrementar las medidas impositivas en su afán de conseguir mayores ingresos para el fisco ${ }^{7}$.

Al propósito, hemos podido reunir datos sobre estos hechos acaecidos en la zona, los que revelan que por entonces fueron muy comunes los movimientos de protesta (acrecentándose más a partir de la segunda mitad del S. XVIII) frente a la política administrativa del gobierno, como lo demuestra la revuelta de 1780 que llegó a abarcar los partidos de Huaylas, Yungay, Carhuaz y Huaraz, cuyas raíces debemos encontrar en las penurias que soportaban los lugareños desde 1779 .

Ahondando en la temática de los hechos, debemos señalar que los sucesos más saltantes ocurrieron en los pueblos de Caráz y Huaraz ${ }^{8}$, en donde los rasgos de la rebelión tomarían aparentemente causas religiosas, siendo las económicas las reales motivaciones.

del Licenciado Diego de Álvarez, en San Luis de Huari (Ancash) y otros, aunque no alcanzando estos iguales números, fueron muy importantes como en Cajamarca, Pallasca (143 obrajeros) y Huamachuco, por citar algunos.

Entre los obrajes existentes en el corregimiento de Huaylas, citados por este investigador, estaban el de Succha (180 indios); Aija (286 indios); Cajamarca de Pira (más de 10 tributarios y 16 muchachos); Huaraz (más de 10 tributarios y 50 muchachos); Carhuaz (30 indios casados y 15 muchachos): Yungay con dos obrajes (en el primero laboraban 50 indios y a veces 100 muchachos, en el segundo más de 50 muchachos); Mato (28 tributarios y 42 muchachos); Huaylas (10 indios y 46 muchachos) y Macate (con 10 tributarios y 80 muchachos).

Cf. Alba Herrera, Augusto. «Reseña histórica de Ancash». En: Ancash Historia y Cultura, t. 1, Lima, CONCYTEC, 1989, p. 65; Bueno, Cosme. Geografía del Perú Virreinal (S. XVIII). publicado por Daniel Valcárcel, Lima, s/p/i (1951), p. 41; GRIDILLA, Alberto. Ancahs (sic) y sus antiguos corregimientos. Arequipa: Ed. La Colmena. S.A., 1936, pp. 326 y 429; SiLVA SANTISTEBAN, Fernando. Los obrajes en el virreinato del Perú. Lima: Publicaciones del Museo Nacional de Historia, 1964, pp. 34, 42 y 130-135.

7 Areche recibió el cargo de Visitador General del Virreinato del Perú, Chile y provincias del Río de la Plata, el 10-03-1776, llegando a Lima el 14-06-1777. Hizo subir al 6\% el impuesto a la Alcabala que era anteriormente del $4 \%$, concitando el descontento general y aunque los indios estaban exonerados de ella se cometían igual injusticias estuvieran o no coludidos los exactores con los corregidores.

Como dato adicional mencionamos que en 1776 ocurrieron alzamientos indígenas en Huánuco, Pasco y Urubamba, extendiéndose los disturbios a Lambayeque, Huaraz, Huancavelica, Arequipa y Moquegua; en 1777 hubo otro levantamiento en Huamalíes con la muerte del corregidor y su familia.

Cf. Del Busto, José Antonio. Compendio de historia del Perú. Lima: Librería Studium, 1988, p. 284; EGUIGUREN, Luis Antonio. Hojas para historia de la emancipación del Perú. T.1. Lima: Imprenta gráfica Tscheuch S.A., 1959, p. 320; Golte, Jürgen. Op. Cit., pp. 143-46; LoRente, Sebastián. Historia del Perú bajo los Austrias. Lima, 1871, p. 169; Mendiburu, Manuel de. Diccionario Histórico Biográfico del Perú. T. II, $2^{\mathrm{a}}$ Ed., con adiciones y notas bibliográficas por Evaristo San Cristóval, Lima, Imprenta Enrique Palacios, 1932, pp. 114 y 117; PALACIO ATARD, Vicente, «Areche y Guirior. Observaciones sobre el fracaso de una visita al Perú». En: Anuario de Estudios Americanos. Sevilla, t. III, 1946, pp. 269-376.

8 Hemos visto por conveniente describir, de manera general, estas revueltas que no han sido del todo resaltadas y valoradas por la historia nacional, pese a los esfuerzos de algunos notables historiadores ancashinos que citamos más adelante. 
Manuel Enrique Valverde Gonzáles - Apuntaciones para la historia del derecho peruano. Un caso de política asistencial en favor de los partidos del corregimiento de Huaylas en el S. XVIII

Es conveniente señalar que algunos curas doctrineros del lugar eran propietarios de grandes extensiones de tierras, donde abusaban de la mano de obra indígena, usufructuándola a cambio de sus servicios religiosos ${ }^{9}$, situación que desembocó en manifestaciones de descontento general, como ya se refirió antes, a causa de los diversos modos como se llevaban a cabo estos excesos ${ }^{10}$.

\section{Debido al abuso de los corregidores, y después de la revolución de Tupac Amaru II, la corona en un intento por frenar los excesos de los primeros implanta el sistema de intendencias, sin embargo muchos de estos funcionarios se insertaron a la nueva organización estatal ocupando algunas subdelegaturas de los Partidos, como fue el caso del marqués de Casa Hermosa ${ }^{11}$.}

\footnotetext{
Del mismo modo, acotamos que no hemos podido espigar más datos referentes tanto a los personajes históricos citados, como de las revueltas indígenas, ni tampoco con relación al tema que motiva este artículo en los legajos existentes en el Archivo Departamental de Ancash, ya que los archivos del Notario Víctor Alvarado no se encuentran en dicho repositorio.

De otra parte, cabe mencionar que en la Sala de Embajadores de la Corte Superior de Justicia de Lima existen tres expedientes relativos a las revueltas en el callejón de Huaylas, el primero referido al 18-01-1780, que son unos autos seguidos contra el sacerdote Juan de la Cruz por ser sumamente inquieto. El segundo, son unos autos criminales contra los reos de los alborotos del pueblo de Caráz en agravio del cura de aquel pueblo, don Marcos de Herrera, Sala del Crimen. Y el tercero, es un cuaderno agregado y relativo al tumulto del pueblo de Guarás, año de 1782. Documentos que pudimos consultar en la debida forma gracias a la autorización concedida por la Presidencia de dicha Corte y a las gestiones de nuestro amigo Rodrigo Nole. De esa guisa, pudimos constatar que se trataban de los mismos expedientes a los que tuvo acceso, y hace referencia, el Dr. Luis A. Eguiguren en su obra colacionada en la nota precedente.

Por todo lo expuesto vid. Alba Herrera, Augusto. Op. Cit., pp. 63-69; y su: Huarás: Historia de un pueblo en transformación. Carás: Ediciones El Inca, 1996, pp. 107-121; ÁlVAREZ BRUN, Félix. Ancash. Una historia regional peruana. Lima: P.L.V., 1970, pp. 113-125; Eguiguren, Luis A. Op. Cit., pp. 349 y 383-392; Golte, J. Op. Cit., pp. 175-176 (el autor no hace referencia alguna al libro del Dr. Eguiguren, que citamos en esta nota); LEWIN, Boleslao. La rebelión de Tupac Amaru. Y los orígenes de la independencia hispanoamericana. Bs. As.: SELA, 1967, p. 179; LOAYZA, Francisco A. Preliminares del incendio, (Colección pequeños grandes libros para la historia americana). T. XIII, Lima, s.p.i, 1947, pp. 90-94, y La verdad desnuda o las dos faces de un obispo, escrita en 1780 por un imparcial religioso, Lima, s.p.i., 1943; O'PHELAN, Scarlett. Op. Cit., pp. 170 y 217 (la autora cuando se refiere a las revueltas de 1774, remite a una cita de pie de página que nos parece inexacta en su contenido, la nota 220, pues tal dato no existe en el AGN, pese a que lo indica como habido en dicho repositorio); REINA LOLI, Manuel. Op. Cit., pp. 30-46; SORIANO INFANTE, Augusto. «Rebeliones indígenas en el corregimiento de Huaylas». En: Rev. El Rumbo. Huaraz, año I, No 4, junio, 1936, pp. 5,6 y 12 in fine. (Colección Reina Loli); VARgas Ugarte, Rubén. Historia general del Perú. T. V. Lima: Milla Batres, 1966, p. 353.

9 Cf. O'PHELAN, S. «Revueltas anticlericales del S. XVIII». En: Historia y Cultura. Lima, No 12, 1979, pp. 131-35.

10 Estos excesos comúnmente consistían en forzar a los indígenas a servicios personales no remunerados, realizar cobros indebidos por encima de lo estipulado referente a diezmos, primicias u obvenciones, expropiarles tierras o riegos de las comunidades por concepto de deudas o repartos, y también eran propietarios de grandes obrajes en donde se explotaba a los indígenas. A guisa de ejemplo tenemos que en 1764, los curacas de las dos guarangas y parcialidades de Rupas, Ecas, Mitma y Llacta de Carhuaz, se quejaban de las vejaciones a las que los sometía el cura Joaquín de Oribe de la Orden de Predicadores, y otros curas, cobrándoles diezmos, primicias y obvenciones en el monto que se les antojaba, no permitiéndoles pagar sus tasas y tributos.

Vid. LoHmann, Op. Cit., pp. 348-51; Archivo Arzobispal de Lima (AAL), Secc. Capítulos: Huaylas, Exp. XIII, Leg. 32, 1764, fol. 7.

11 El aludido marqués fue el último Gobernador Corregidor del Corregimiento de Huaylas, que pertenecía al Arzobispado de Lima. Este corregimiento pagaba por cada año una alcabala de 1120 ps., y la suma permitida por repartimiento era de 140000 ps.
} 
Manuel Enrique Valverde Gonzáles - Apuntaciones para la historia del derecho peruano. Un caso de política asistencial en favor de los partidos del corregimiento de Huaylas en el S. XVIII

\subsection{La revuelta de Caráz}

Con referencia a Caráz, la miseria en la que se encontraban sumidos los indígenas, la explotación de los grandes propietarios y el abuso en el cobro de los tributos, tenían exasperados a sus pobladores; motivando estos males que se busque ocasión propicia para sublevarse. Es de ese modo que al propalarse la noticia entre la población de la desaparición de la efigie de la Virgen del Rosario, los indios y mestizos bajaron a la ciudad el 14 de noviembre de 1780 en son de alzamiento.

Sucedió que era párroco de la doctrina de San Ildefonso de Caráz el Dr. Marcos de Herrera quien observó que la mencionada imagen se hallaba bastante deteriorada y mal conformada por lo que decidió contratar los servicios de un escultor para que realice las reparaciones necesarias, trasladando para esto la imagen a la casa parroquial. Motivó este hecho comentarios, por parte de los soliviantadores, que la Virgen había sido degollada y por lo tanto se tenía que hacer lo mismo con el cura, el escultor y los demás que habían conducido la imagen.

El sacerdote logró, después de denodados esfuerzos, calmar los caldeados ánimos, pero con muy poco éxito, pues pronto comenzó a correr el rumor que la imagen existente en la casa cural era otra y no la original de la Virgen del Rosario que ellos veneraban; luego, los amotinados pasaron a demoler la casa parroquial y la de otros vecinos del lugar; llegando a alcanzar graves proporciones ya que de nada valieron los intentos de sacar en procesión al Santísimo Sacramento, porque respondieron a tal acto con una lluvia de piedras que llegaron a romper algunas varas del palio.

Los insurrectos tomaron la ciudad de Caráz por espacio de cuatro días. El 16 de noviembre, el corregidor marqués de Casa Hermosa tuvo noticias del alzamiento cuando estaba regresando del pueblo de Macate y dispuso que las milicias de Huata y del valle de Guacra pasaran a sofocar el movimiento. Llegó el día 18 a Caráz, trabándose reñidos encuentros con desiguales pérdidas entrambas partes; los derrotados procuraron ganar las alturas de la cordillera blanca, aunque con poco éxito.

El corregidor tomó prisioneros a varios revoltosos y luego procedió a administrar justicia, aplicó la pena de horca a tres, mandó descuartizar sus restos, sembrando los cuerpos, cabezas y manos en distintos parajes por donde se hizo firme la resistencia, y en los sitios que tuvo por conveniente. Azotó a setenta y tres, rapó cabezas y fueron pasados bajo la horca; dando cuenta pronto de las acciones tomadas al virrey Jáuregui el 21 de noviembre de 1780 
Manuel Enrique Valverde Gonzáles - Apuntaciones para la historia del derecho peruano. Un caso de política asistencial en favor de los partidos del corregimiento de Huaylas en el S. XVIII

y solicitándole la aprobación de tales medidas que las aplicó sin haber contado con la autorización de Lima. Contestole la misiva el Visitador Areche el día 4 de diciembre del mismo año, aprobando la actitud del corregidor por hacer respetar el poder del rey, su jurisdicción y la autoridad con que tenía en ese territorio. Finalmente, y a instancias del Protector de Naturales José Baquíjano y Carrillo ${ }^{12}$, los revoltosos prisioneros fueron indultados mediante una Carta Provisión Real del 25 de enero de 1781 dictada por Carlos III, procediéndose a liberar a todos los detenidos y dejándose de perseguir a los fugados.

Estos hechos han sido descritos más ordenadamente por el notable investigador y diplomático argentino Enrique Ruíz Guiñazú, pues el Dr. Eguiguren menciona este hecho como si hubiera sido el mismo que la denominada Revuelta de las Alcabalas ocurrida en la ciudad de Huaraz, pese a que éste último pudo consultar directamente los documentos judiciales relativos a las revueltas, a los que también hemos tenido acceso.

\subsection{Revuelta de las Alcabalas}

En lo concerniente a las revueltas de 1779-1780 (llamadas de las Alcabalas por el investigador Reina Loli), el Dr. Eguiguren nos trae una minuciosa información de estos alborotos, producto de sus investigaciones realizadas en el Archivo General de Indias y en los archivos de la Corte Superior de Lima, ya realizadas escuetamente antes por el Dr. Francisco Loayza. Asimismo complementaremos este suceso con otros datos aportados por los investigadores ancashinos Augusto Soriano Infante y Manuel Reina Loli, quienes hallaron pormenores de dichas trapatiestas en los archivos notariales de Huaraz; a lo que sumaremos los datos obtenidos por nuestra parte de los expedientes conservados en la Corte Superior de Lima.

Los sucesos empiezan cuando el sacerdote betlemita José de la Cruz se constituyó en director intelectual del anterior corregidor don Pedro Pablo Pomar $^{13}$, quienes, de consuno, empezaron a recorrer las doctrinas de Caráz,

\footnotetext{
12 Sobre la vida y cargos desempeñados por Baquíjano ver: LOHMANN VILLENA, Guillermo. Los ministros de la Real Audiencia de Lima (1700-1821). Sevilla: C.S.I.C., E.E.H.A,, 1974, p. 9 y TAURO DEL PINO, Alberto. Enciclopedia ilustrada del Perú. Lima: Peisa, 1988, t. 1, pp. 242-244.

13 Este personaje resulta de curiosa trayectoria, pues sobre él encontramos datos referidos a su espíritu liberal e ilustrado, lo que explicaría su relación con el sacerdote betlemita Juan de la Cruz en tratar de levantar a los pueblos contra la recolección ordenada por el virrey Guirior. Empero, hay que anotar que fue el mismo Guirior quien lo designó Corregidor interino, cargo que ejerció hasta 1779.

Según afirma Guibovich Pérez, cuando el citado Pedro Pablo Pomar vino de la península para asumir el cargo de corregidor de Huaylas, una vez concluido su gobierno, dejó sus libros a Santiago de Urquizu. Estos trataban de las siguientes materias: las Cuestiones sobre la Enciclopedia, el Diccionario philosóphico y
} 
Manuel Enrique Valverde Gonzáles - Apuntaciones para la historia del derecho peruano. Un caso de política asistencial en favor de los partidos del corregimiento de Huaylas en el S. XVIII

Huaylas y Macate e influyeron en los indígenas de aquellos lugares para que rechazaran la recolección que había ordenado el Virrey Guirior, quien dispuso a que contribuyeran con el salario del corregidor Casa Hermosa en recompensa de la renuncia que había hecho del repartimiento. Muy pronto el fraile se convirtió en un soliviantador de las masas, apoyando a cuantos lucharan contra la autoridad, razón por la cual el nuevo corregidor, marqués de Casa Hermosa, pidió al virrey que interviniera a fin que haga salir de su corregimiento al religioso perturbador (31-12-1779). Finalidad que se logró, y conjuntamente se hizo salir también a Juan de Florencia empleado de Pomar, en febrero de 1780, quien había realizado acciones proselitistas a favor de las revueltas; todo debido a que en enero de 1780 se pretendió ultimar a Antonio López, comisionado de Miguel de Enderica (administrador del ramo de alcabalas nombrado por Areche en 1779), quien, de no haber huido, hubiera perecido en el pueblo. Esta actitud de los naturales fue equivocada porque estaban exentos de dicho pago, pero todo se debió a la provocación de los mestizos.

De esta manera empieza en el corregimiento una etapa creciente de inquietud social, hasta que en febrero de 1780 amanecieron fijados en la plaza de la ciudad de Huaraz dos pasquines en los que amenazaban al comisionado de alcabalas, dando lugar a que el marqués ordenase se realicen rondas armadas por las calles del pueblo, encontrándose una de estas rondas con otra que había organizado el comisionado, enfrentándose por equivocación con un saldo de varios heridos, excitando más aún los ánimos ya trasegados por el alzamiento. El marqués de Casa Hermosa atribuyó la autoría de tales pasquines al sacerdote de la Cruz.

El 8 de febrero de 1780 se sublevó la población huaracina, congregando a más de 2000 indios en los cerros aledaños. El marqués los mandó convocar a la plaza de la ciudad, presentándose a ella los insurrectos, portando rejones, espadas, dagas, piedras y batiendo banderas sui generis, apedrearon al corregidor tan pronto como lo vieron, persiguiéndolo hasta su casa $\mathrm{y}$, de no ser por un sacerdote que esos momentos estaba celebrando misa, quien sacó al Santísimo Sacramento a la puerta del templo que estaba enfrente a la

\footnotetext{
las Misceláneas de Voltaire, el Sistema de la naturaleza de Holbach, el Cristianismo descubierto de NicolásAntoine Boulanger y el «Aretino». También demostró tener inquietudes sobre temas equinos, dado que se le atribuye haber presentado un discurso el año 1784 ante la Real Sociedad Aragonesa, sobre las castas de los caballos de España, su decadencia y algunos medios de restablecerlos.

Cf. Moreno CABrián, Alfredo. «El marqués de Casa Hermosa, corregidor de Huaylas e intendente de Puno». En: Anuario de Estudios Atlánticos. N²4, 1978, p. 102; GuIBOVICH PÉREZ, Pedro. «La literatura francesa en el virreinato del Perú: comercio legal y contrabando en el período tardío colonial». En: Histórica. $\mathrm{N}^{\circ} 31$, 2007, p. 103.
} 
Manuel Enrique Valverde Gonzáles - Apuntaciones para la historia del derecho peruano. Un caso de política asistencial en favor de los partidos del corregimiento de Huaylas en el S. XVIII

casa del corregidor, no se hubieran apaciguado los ánimos. Los amotinados continuaron la hostilidad contra el curaca de forasteros y contra los que habían actuado en la revisita de tributarios; pasaron pronto a la cárcel dando libertad a los presos; sacaron las puertas de la casa del curaca principal Patricio Gonzáles Viracochacho y de algunos vecinos, quemándolas luego.

La causa de todo fue la aplicación del tributo a los mestizos y de los doblados derechos de alcabala ordenada por Areche. El corregidor ordenó la salida del sacerdote de la Cruz, quien se negó a salir de la provincia pasando a Recuay, donde pretendió mover al vecindario haciéndole creer que irían 500 soldados para imponerles tributos y arrasar la ciudad, pero fue apresado en dicha ciudad, confinándosele en Lima; haciéndose lo mismo con Juan de Florencia, a quien se le extrañó a Trujillo, donde residía su mujer, bajo sanción de ser internado a la Real Cárcel de la Corte de Lima si se atrevía a salir de dicha ciudad. El Alcalde del Crimen, Ambrocio Cerdán y Pontero ${ }^{14}$, fue el encargado de conocer los memoriales del marqués en marzo de 1780 y D. Juan Bazo Berri fue nombrado visitador de la provincia para esclarecer la verdad sobre los hechos anteriores al tumulto.

El 12 de mayo de 1780 el Marqués de Casa Hermosa comunicó al virrey que el P. de la Cruz dejaba la ciudad de Huaraz y navegaba rumbo a Guayaquil, además se encarceló a un criado suyo en la Real Cárcel de la Corte y se dictaban disposiciones contra una moza llamada Martina Zolanas, que fue sirvienta del anterior corregidor Pedro Pablo Pomar.

Nuevamente, el 25 de diciembre de 1781 empezaron a aparecer pasquines contra el estanco del tabaco, debido a que el teniente de la renta José Gordillo había recorrido la provincia añadiendo otros estanquillos; indicándose en tales pasquines que si había existido en la tierra de arriba dos Tupac Amarus, allí habrían doscientos. Antes de las 24 horas el Teniente Alguacil Mayor Gabriel de Sal y Rosas retiró el pasquín, pero la noticia del panfleto ya se había propalado por toda la ciudad y la gente que recurría a comprar tabaco trataba al estanquillero Miguel de Ugarte y a su esposa con mucha insolencia.

La presencia de estos personajes -Gordillo y Ugarte-, se convirtió en motivo de rebeldía por parte de los lugareños, por lo que el marqués de Casa Hermosa les pidió que saliesen de la provincia, negándose estos ha hacerlo por no depender de su autoridad. Areche y el Fiscal de la Audiencia, Francisco Antonio Moreno y Díaz de Escandón, se mostraron contrarios a tal salida,

14 Para mayores datos sobre este personaje vid. LohmAnN VillenA, Guillermo. Los ministros de la Real Audiencia de Lima (1700-1821). Sevilla: C.S.I.C., E.E.H.A, 1974, p. 33. 
Manuel Enrique Valverde Gonzáles - Apuntaciones para la historia del derecho peruano. Un caso de política asistencial en favor de los partidos del corregimiento de Huaylas en el S. XVIII

reprendiendo Areche al corregidor por permitir tales alborotos, ya que éstos llevaban a resultados como la revolución de Tupac Amaru II en el Cuzco, quien exigió, se saquen a los corregidores y curas que no fueran de su agrado.

El día 3 de febrero de 1782 amaneció un pasquín en el cementerio de la iglesia de la ciudad, que despotricaba contra jueces y gobernadores. Se pusieron otros pasquines más en los pueblos de Yungay, amenazando al estanquillero Diego Montes, sucediendo lo mismo en Carhuaz, Mato, Huaylas, Macate, Recuay, estancia de Mancos y valle de Guacra, que era donde estaba la fuerza principal de la provincia por "la mucha mestizada que había en ellos".

Ese mismo día el corregidor prohibió toda actividad pública, y el día 4 ordenó al Coronel de Regimiento de Caráz Cayetano Pajuelo que se apertrechara bien. El 25 de febrero Jáuregui escribía al corregidor previniéndole que apurara todos los medios posibles para apaciguar los ánimos y que le avisara con anticipación los auxilios que requiriera para hacer respetar el orden en la provincia. De todas maneras el 5 de mayo por la noche, la casa del corregidor en Caráz fue atacada, llegándosele a matar dos caballos tordillos, dando lugar a otras trapatiestas que fueron duramente reprimidas por el corregidor Francisco de Mesa Ponte y Castilla. Con posterioridad se produjeron nuevas protestas en 1784 (en Huaylas) y 1788 (en Carhuaz). También en la zona del callejón de los Conchucos se suscitaron hechos similares, como fue en Chacas (20 de octubre de 1789) y Pomabamba (6 de septiembre de 1790) $)^{15}$.

\section{DEL CORREGIDOR MARQUÉS DE CASA HERMOSA}

Conviene ocuparnos también de este personaje que tuvo actuación descollante tanto en los hechos belicosos descritos como en el tema que nos convoca para realizar este artículo.

El aludido marqués se llamaba Francisco José de Mesa Ponte y Castilla, Caballero profeso de la Orden de Santiago, nació en Canarias en donde su padre don José Jacinto de Mesa y Castilla ejerció el cargo de Coronel del Regimiento de Tacorante, en las islas de Tenerife. También él, como su padre, sirvió en el mismo regimiento por veinticuatro años llegando a ser Teniente Coronel. Fue entonces cuando se le nombró corregidor de la

${ }^{15}$ Cf. Ruíz Guiñazú, Enrique. La Tradición en América, (Colección Austral No 1155). Argentina: Ed. Espasa Calpe S.A., 1953, Cap. XII «La iconolatría incaica y el tumulto de Caráz», pp. 154-156. Vid. además REINA LOLI, Manuel. Rebeliones indígenas en el S. XVIII en Huailas. Huaraz: UNASAM, 1980, pp. 1-16 (quien se acoda en el anterior autor para desarrollar su obra); CORTE SUPERIOR DE JUSTICIA DE LIMA, SALA DE EMBAJADORES. Autos criminales contra los reos de los alborotos del pueblo de Caráz contra el cura de aquel pueblo don Marcos de Herrera tramitados ante la Sala del Crimen de la Real Audiencia, 1780. 
Manuel Enrique Valverde Gonzáles - Apuntaciones para la historia del derecho peruano. Un caso de política asistencial en favor de los partidos del corregimiento de Huaylas en el S. XVIII

provincia de Huaylas (según Rodríguez Casado el 17.VII.1767, en tanto que Moreno Cebrián afirma que fue el 12.X.1766), trayendo en su viaje a América las órdenes a las autoridades ecuatorianas para expulsar a los jesuitas, conforme nos menciona Vicente Rodríguez Casado. Llega a asumir el cargo para su primer período de corregidor de la provincia de Huaylas en octubre de 1769, hasta aproximadamente octubre de 1774, siendo reemplazado por Pedro Pablo Pomar; volviendo a retomar el cargo en noviembre de 1779 hasta 1784 (al haber solicitado tal puesto el 22 de abril de 1776). Al respecto, cabe destacarse que el P. Soriano Infante consigna fechas distintas, sosteniendo que de 1767 a 1772 ocupó el cargo de corregidor de la provincia de Huaylas el general Fermín Delgado y Peralta. De 1772 a 1775 Rafael Solís y de 1775 a 1781 Pedro Pablo Pomar; sucediéndolo recién en 1781 el marqués de Casa Hermosa. Datos que se contradicen con los sucesos acaecidos en la época, pues en la revuelta de 1774 ya era corregidor el mentado marqués, conforme lo manifiesta el historiador Reina Loli en su obra citada, emergiendo tal hecho también de los documentos consultados por nuestra parte.

En su época de corregidor organizó la Real Hacienda y las milicias, formando con ellas cinco regimientos de infantería y uno de caballería; ordenó levantar las estadísticas de la población con arreglo a las leyes generales y consiguió intensificar el trabajo en las minas, dándose el caso que en el año de 1772 promueve un expediente sobre el mayor aumento y adelantamiento de las minas que se habían descubierto en la provincia, logrando que los remates de las mismas se hagan en la capital del corregimiento y ya no en la ciudad de Cerro de Pasco por ser muy lejana. Debido a esto, al rendir las cuentas en su Juicio de Residencia fue merecedor que se le declarase buen ministro y juez recto, digno para ocupar mayores empleos.

Es en esta etapa en la que le tocó intervenir en las revueltas indígenas ocurridas en los términos de Yungay y Huaraz, dándoles pronto fin; siendo uno de los primeros en dar aviso que se avecindaba una rebelión mayor y de más funestas consecuencias, de lo que hizo saber al virrey Guirior, incluso proponiéndole extinguir el repartimiento en su corregimiento y que, más bien, se le asegurase una renta de 8000 pesos anuales que podían recaudarse con una pequeña cuota que erogasen los indios, propuesta hecha en 1779, la que hizo suya Guirior, pero Areche le dio muy dilatados trámites y lo frustró remitiéndolo a la Corte, en donde nada llegó a resolverse, estando a favor del plan gran parte de los pueblos. Opinaba Areche, con relación al caso, que había algunas personas que decían que el señor marqués hacía tal propuesta por haber gobernado antes el corregimiento de Huaylas y por haber hecho un nuevo repartimiento, creyendo seguir en el cargo por dos o más años, y eso 
Manuel Enrique Valverde Gonzáles - Apuntaciones para la historia del derecho peruano. Un caso de política asistencial en favor de los partidos del corregimiento de Huaylas en el S. XVIII

motivaba su pedido, y si ofrecía no efectuar reparto alguno era porque ya lo tenía repartido e iba a cobrar con las otras ventajas que solicitaba de sueldo.

Aún realizando tal petición, viose obligado a cumplir las órdenes del gobierno peruano sobre tributos nuevos y reforma de los antiguos en aquellas regiones de la provincia, como eran las aduanas, alcabalas, matrículas de tributarios, rentas de tabacos, etc. La prontitud con que sofocó las revueltas indígenas le permitió enviar una expedición de tropas a Casma conforme a las órdenes del virrey ${ }^{16}$.

En 1784 (y no en 1785 como lo dicen Mendiburu y Rodríguez Casado), ocupa el cargo de Subdelegado de la misma provincia de Huaylas, al crearse la intendencia de Tarma, cargo que ocupa hasta el 13 de noviembre de 1785 . Luego, con fecha 23 de enero de 1789, se le asciende a Coronel con declaración de sueldo y antigüedad desde el 11 de noviembre de 1779, en tanto que por decreto del 7 de marzo del mismo año, fue nombrado Gobernador Intendente de la provincia de Puno en el distrito de la Real Audiencia de Charcas, dependiente por ese entonces del virreinato de Buenos Aires.

Fue el segundo Intendente que tuvo Puno, cuyo cargo se le entregó el 1 de enero de 1790 por el Dr. José Joaquín Contreras, abogado de Chuquisaca, que servía el cargo de Teniente Gobernador. En 1794, por cuestiones de rivalidad, se le inicia secretamente un Juicio de Residencia que concluye en 1798, siendo absuelto de los principales cargos, pero condenado al pago de costas (él ya había dejado su cargo en 1795 por razones de salud, quedando en calidad de encargado don José Antonio de Campos por orden del Virrey de Buenos Aires), fallo que apeló ante la junta de la Real Audiencia de Buenos Aires, cuyo recurso se dirige al Consejo de Indias el 10 de febrero de 1800, órgano que reunido en la Sala de Justicia pronunció el 19 de agosto del mismo año la sentencia definitiva de completo acuerdo con los deseos del marqués, pagándosele así las indemnizaciones que pedía y condenándoseles a sus acusadores al pago de los gastos en que había incurrido el susodicho marqués.

A diferencia de lo sostenido por Rodríguez Casado, hemos hallado por nuestra parte una Real Cédula fechada en 1801 por la cual se dispone incoarle juicio de Residencia al marqués de Casa Hermosa, proceso que tenía que correr a cargo de José Gonzáles nuevo Gobernador de Puno.

\footnotetext{
${ }^{16}$ Es necesario anotar que el 7 de diciembre de 1780, mediante un bando del Virrey Jáuregui se anulaban los repartimientos de los corregidores y se les asignaba un sueldo por cuenta de la Real Hacienda. Esta supresión fuer una decisión unilateral del virreinato peruano, la misma que encontró eco en la metrópoli al expedirse la Real orden del 1 de junio de 1781, por la cual se daba fin a este régimen.
} 
Manuel Enrique Valverde Gonzáles - Apuntaciones para la historia del derecho peruano. Un caso de política asistencial en favor de los partidos del corregimiento de Huaylas en el S. XVIII

Como Intendente de Puno elevó reiteradas peticiones ante el Consejo de Indias para que se permita el comercio neutral para el Perú, alegando que debía recuperarse de la suspensión que había sufrido durante el juicio al que se vio sometido en 1794. Peticiones que no fueron aceptadas por el colegiado indiano.

Finalmente podemos acotar que el referido marquesado le fue concedido el 10 de octubre de 1776, con el Vizcondado previo de San Carlos a don Francisco de Mesa y Ponte, Caballero de Santiago, según sostiene Atienza; en tanto que Izcue apuntala que fue en $1792^{17}$.

\section{LA PETICIÓN DE AUXILIO DE LOS TRIBUTARIOS}

El documento que motiva el presente comentario, es un expediente promovido por los curacas de la doctrina de la provincia de Huaylas ${ }^{18}$ con el objeto de lograr que se les auxilie con los fondos existentes en el Caja de Censos de la provincia para así poder aliviar la difícil situación económica por la que estaban atravesando producto de una sequía y una epidemia de viruela.

Cf. MORENO CEBRIÁN, Alfredo. El corregidor de indios y la economía peruana del siglo XVIII (Los repartos forzosos de mercancías). Madrid: C.S.I.C, 1978, p. 609 y ss.

17 Cf. AtienZa, Julio de. Nobiliario español: Diccionario heráldico de apellidos españoles y de títulos nobiliarios. Madrid: Ed. Aguilar, 1959, p. 828; GolTe, J. Op. Cit., p. 196; IZCUE, Luis de. La nobleza titulada en el Perú colonial. $2^{\text {a }}$ Ed. Lima: Cervantes, 1929; Mendiburu, Manuel de. Op. Cit. $2^{\text {a }}$ ed. T. VII. Lima, 1933, pp. 376-37; t. II, Lima, 1932, pp. 116-117, y t. IV, Lima, 1932, pp. 456 y 459; MORENO CEBRIÁN, Alfredo. El corregidor de indios..., pp. 568-579 y passim; y «El marqués...», pp. 18 y ss; PARRÓN SALAS, Carmen, De las reformas borbónicas a la república: El consulado y el comercio marítimo de Lima, 1778-1821. Murcia: Imprenta de la Academia General del Aire, 1995, pp. 438-440; ReINA Loli, Manuel. Op. Cit., p. 22; RoDríGUEZ CASADO, Vicente. «Causa seguida contra el marqués de Casa Hermosa, gobernador intendente de Puno». En: Anuario de Estudios Americanos. T. III. Sevilla, 1946, pp. 957-68; SORIANO INFANTE, A., Corregidores de la provincia..., p. 12; y Biblioteca Nacional del Perú, Sección manuscritos, C. 2757 (1772), fs. 1-4 y D. 60 (1801), fs. 1.

18 Referente a la provincia de Huaylas Cosme Bueno, después de mencionarnos las bondades de esta ubérrima zona, pasa a decirnos que esta provincia constaba de 12 curatos y dos pueblos de otro cuya cabeza está en la de Santa (que es el pueblo de Yaután), siendo los siguientes: 1) Huaraz; 2) Recuay; 3) Marca; 4) Carhuaz; 5) Yungay -precisando que en 1725 desapareció el pueblo de Ancash de cerca de 1500 habitantes a causa de un alud-; 6) Caráz; 7) Huaylas; 8) Mato; 9) Aija; 10) Cotaparaco; 11) Pararín y 12) Pampas.

Otro autor, Alcedo y Herrera, refiriéndose a la provincia y corregimiento de Guailas nos dice que su repartimiento era de 1400 ps., pagando 10120 ps. al año de alcabala. La población constaba de 30 pueblos y la capital era Huaraz, siendo los otros: Recuay, Olleros, Marca, Ichoca, Pampa, Huambo, Carhuaz, Yungay, Caráz, Huaylas, Macate, Lacramarca, Aija, Hicayán, Sudcha, Coris, Huacllán, Cotaparazo, Tanacochas, Cochapetí, Malvas, Huallancahuambo, Colchahuanca, Pararín, Pampas, Pira, Llaccllín, Cajamarquilla, Huallón y Huanchay.

La descripción de Haënke es similar a las anteriores, acotando que su población contenía 12 doctrinas y 20 pueblos anejos, habitados por 40822 almas, entre ellas 3604 españoles, 20935 indios y el crecido número de 15971 mestizos, siendo los demás pardos libres y esclavos. Todos estos habitantes eran de los más cultos y despejados que los de otras sierras y se distinguían por su laboriosidad.

Cf. AlCEDO y HerRerA, Antonio de. Diccionario geográfico histórico de las indias occidentales o América. T.2. Madrid: Imprenta Benito Cano, 1786-89, pp. 254-55; BUENO, Cosme. Op. Cit., pp. 41-42.; VÁsQueZ DE EsPINOZA, Antonio. Descripción de las indias occidentales. Madrid (Biblioteca de autores españoles), 1969, pp. 333-34. y 
Manuel Enrique Valverde Gonzáles - Apuntaciones para la historia del derecho peruano. Un caso de política asistencial en favor de los partidos del corregimiento de Huaylas en el S. XVIII

El grupo de autoridades indígenas fue numeroso y está conformado por los representantes de todas las parcialidades del Partido de Huaylas. En este caso consignaremos los nombres de las ciudades de la forma como se registran en el legajo consultado. Las citadas autoridades fueron: Patricio Gonsales Rimaicochachin ${ }^{19}$, Carlos Gonsales, Thomás Rosales, Joseph Ysidro y Santos Solis, de la doctrina de Guarás; Thomas Janan, de Macate; Estevan Chauca, Juan Flores y Clemente Alba de Guailas; Thomás Pariachi, Pedro Blas, Estevan Gerónimo y Ambrocio Rivas, de Carás; Francisco Torivio, Antonio Baltasar Riques, Antonio Felis, Jacinto Montes y Pasqual Mathías Sarón, de Yungai; Luis Cochachin, Antonio Paredes, Antonio Torivio y Miguel Yanac, de Carguas; Juan de la Cruz García, Manuel Francisco Rafael Ynquiltopaynga y Joseph Ancelmo Yaruguamán, de Requay; Joseph Gregorio Caricambo, Joseph Asencio Padilla, Eucevio Asencio Padilla y Domingo Espíritu Vega Chauca, de Marca; Joseph Luna, Domingo Andrade y Andrés Bartolo, de la Guaranga de Pararín; Rafael Colquipoma ${ }^{20}$, Tiburcio Quirós, Pedro Ermenegildo Guamán

HAËNKE, Tadeo. Descripción del Perú. Lima: Imp. El Lucero, 1901, pp. 204-205. [Sobre este último autor, según Porras Barrenechea en su libro Fuentes históricas peruanas, la autoría real sobre la obra le correspondería a Felipe Bauzá y no a Haënke. De igual parecer son los historiadores Laurio H. Destefani y Donald Cutter en su obra: Tadeo Haënke y el final de una vieja polémica, Bs. As., Secretaría de Estado de la Marina, 1966, p. 106].

19 Este curaca, Patricio Gonsáles Rimaicochachín, es nombrado por Eguiguren como Gonsáles Viracochacho, Golte lo transcribe (del mismo documento consultado en el Archivo General de Indias) como Rimaycochachi y en el legajo del AGN consultado por nosotros lo encontramos como Patricio Gonsales Rimaicochachín. Es pertinente señalar que perteneció a una estirpe de autoridades de comunidad, tal como emerge de los trabajos de Varón Gabai y de Espinoza Soriano, quienes aportan datos sobre esta autoridad indígena, el mismo que era hermano de Carlos Gonsales Rimaicochachín, el otro curaca peticionante y, ambos fueron hijos de Pedro Gonsales Rimaicochachín.

Cf. Eguiguren. Op. Cit., p. 388; EspinOZA Soriano, Waldemar. Huaraz: Poder, sociedad y economía en los siglos XV y XVI. Lima: Seminario de Estudios Rurales Andinos, UNMSM, 1978, edición mimeografiada; GoLTE, Op. Cit., p. 176, y VARÓN GABAI, Rafael. Curacas y encomenderos. Acomodamiento nativo en Huaraz, siglos XVIXVII. Lima: P.L.V, 1980, pp. 80-81.

20 En 1771 el común de indios del pueblo de San Pedro de Tapacocha inicia unos autos sobre la sucesión legítima del cacicazgo del repartimiento de Marca contra el curaca interino don Rafael Colquipoma en favor de Francisco Guzmán quien provenía del linaje de los Caquixambo y se suponía que era a quien le correspondía dicho cargo por derecho de sangre, acusándosele al citado Colquipona de ser cruel y sanguinario.

Ocurrió que el genearca de Guzmán, el curaca Luis Caquixambo, había fallecido sin dejar descendientes y ante la falta de sucesores, el Corregidor y Justicia Mayor de la provincia don Manuel de Yzuriaga nombró en 1730 a Francisco de la Cruz Colquipoma como curaca interino, tal como sostenía el marqués de Casa Hermosa en carta del 17 de junio de 1771 (f. 5). A la muerte de éste y creyéndose que el cacicazgo era hereditario, toma la posta su sobrino Domingo Colquipoma, quien luego de ejercer el cargo por cuatro años le transmite dicha encargatura a su primo Diego Colquipoma, y a la muerte de éste ocupa el cargo Rafael Colquipoma, detentando el cacicazgo por treinta años.

Los testimonios de los lugareños le daban la razón a Francisco Guzmán, sin embargo no pudimos saber exactamente en qué acabó tal litigio, pues el expedientillo se encuentra incompleto; lo que podemos afirmar es que en la relación de curacas peticionantes del documento motivo del presente artículo, aparece un Joseph Gregorio Caricambo como perteneciente a Marca y el mencionado Rafael Colquipoma como curaca de Cotaparaco (estancia muy cercana a la de Marca), no figurando con cargo alguno Francisco Guzmán; por lo que estando a los documentos glosados, podemos aseverar que el dicho Joseph Gregorio era de la estirpe de los Caquisambo, en consecuencia tendríamos que dos lugares, Marca y Cotaparaco, estuvieron bajo la égida de una misma línea de autoridades nativas.

AGN. Secc. Derecho Indígena, Leg. 20, c. 340, 1771; 6 fs. 
Manuel Enrique Valverde Gonzáles - Apuntaciones para la historia del derecho peruano. Un caso de política asistencial en favor de los partidos del corregimiento de Huaylas en el S. XVIII

y Francisco Benito, curacas de Cotaparaco; Pedro Matheo Gonsáles, Joseph Tolentino, Pedro Calistro, Sebastián Collas, Miguel Quiñones, Juan Joseph Auquinibín y Juan Torivio García, de Pampas; y Eduardo Villafranca, curaca de Cochabamba ${ }^{21}$.

El petitorio está dirigido a que se les socorra a los indios de dicha provincia con los rezagos de la Caja de Censos, por hallarse estos en el más lamentable estado de pobreza. Abundando en argumentos, alegan que sufren el azote de una epidemia de viruela que había causado una gran mortandad, sobre todo en la población infantil.

Como era de rigor, el petitorio lo elevan ante el Corregidor Gobernador de la provincia de Huaylas, función que estaba en manos del marqués de Casa Hermosa, quien en carta del 22 de julio de 1780 expone tal situación al virrey Agustín de Jáuregui, precisándole "... que quanto manifiesta la información que he recibido ha pasado por ojos por haberlo así reconocido en la visita que he hecho, que me han movido a compasión y lo he reconocido con más inmediación en las faltas de enteros de reales tributos..."22.

Adicionando probanzas a su solicitud, los peticionarios llegan a presentar por testigos a ocho personas notables de la zona, los que a la sazón eran Pedro de Larrea, Isidro Francisco del Barrio, Manuel de Robles, Joseph María del Barrio, Domingo Gonzáles, Mariano Vergara, Joaquín Calvente y Norverto Macedo $^{23}$, quienes de acuerdo a los usos procedimentales de la época, absuel-

${ }^{21}$ AGN Secc. Derecho Indígena. Leg. 35, c. 715, 1780, fs. 1 y 1v.

${ }^{22}$ Continuando dice: “...no obstante de lo que contaba de la información, y tenía reconocido, para mayor formalidad pasé un oficio á los vicarios de la provincia para que me instruyan mejor y por ello consta calificado quanto se há expuesto, y en cumplimiento de mi cargo y movido a lástima conociendo la gran necesidad de estos miserables, soy de parecer que la solicitud de que se les auxilie con los rezagos que tiene la Caja General de Censos, es de justicia, sobre que determinará V.E. lo que fuese de su justificado arbitrio. Huaraz y julio de 1780. (Firma del marqués)."

Recibida tal misiva, el virrey Jáuregui envía una comunicación al Visitador Areche, cuyo tenor decía: "Muy señor mío. El corregidor de Guaylas, me ha informado del lamentable estado de pobreza a que han venido a reducirse los indios de aquella provincia, clasificándolo con una información que he recibido sobre el asunto, y siendo su objeto a que se los auxilie con los rezagos que tiene en la Caja General de Censos; he resuelto pasar a V.S, dicho informe y diligencia para que se sirva resolver lo que estimare por más conveniente en razón de la citada pretensión. Dios guarde V.S. muchos años. Lima 22 de septiembre de 1780. Una firma (Jáuregui)."

Cf. AGN Leg. 35, fs. 12, 12v y 14.

23 A continuación ofrecemos una breve descripción de estos personajes:

a) Pedro de Larrea, era Teniente Coronel del regimiento de caballería del pueblo de Huaraz. Describe la gran mortandad que había producido la epidemia de viruela y sequía, contaba con 35 años al momento de deponer como testigo.

AGN. Leg. 35 fs. 2v.

b) Isidro Francisco del Barrio, Coronel, de 63 años, natural de Madrid, afirma en su testimonio lo mismo que el anterior testigo (fojas 3 y 3v). Fue Administrador de Tabaco durante la revuelta de Huaraz en 1780, 
Manuel Enrique Valverde Gonzáles - Apuntaciones para la historia del derecho peruano. Un caso de política asistencial en favor de los partidos del corregimiento de Huaylas en el S. XVIII

ven las preguntas en formato uniforme, pues las mismas versan sobre temas similares; culminando esta pieza con la suscripción del marqués así como las de Cayetano de Utorbeli y Juan José Carbajal en calidad de fedatarios.

A estas testimoniales se incorporan las de los curas de las doctrinas de la provincia, quienes a pedido del marqués, corroboran los hechos descriptos por los deponentes primeros y particularmente el vicario de Huaylas, don Marcos de Herrera dice que esta difícil situación de los lugareños “... los lleva a estar esclavizados en las haciendas con un sueldo de 2 reales siéndoles imposible a los indigenas mantener a sus familias" 24 .

Con fecha 20 de septiembre, el virrey Jáuregui pasa el expediente al Visitador General y Superintendente de la Real Hacienda José Antonio de Areche,

también Teniente de Corregidor de la provincia de Huaylas en 1779, cuando era Capitán Comandante y además fue Juez Subsidiario del Corregidor Manuel Gregorio García en 1766. Fue casado con doña María Antonia Gutiérrez y Posada, teniendo como hijos a María Antonia, Joseph, Manuel, Joseph, María y María Luisa del Barrio y Gutiérrez. Otorgó testamento el 07 de junio de 1759.

Eguiguren, Op. Cit., p. 399; Soriano Infante. Art. Cit., p. 12; MOREno Cebrián, Alfredo, «El marqués de casa hermosa, corregidor de Huaylas e intendente de puno». En: Anuario de Estudios Atlánticos. N²4, 1978, p. 104; AAL, Secc. Capítulos: Carhuaz, Leg. 32, Exp. 32. xix, 1766, fs 1v y 2; AGN. Escribano José de Aizcorbe, 1759-1762 (09), fol. 102 y 103v.

c) Manuel de Robles, Capitán, español, de 51 años, tenía una estancia en Cochabamba, reafirma lo dicho por los testigos anteriores. Legajo citado, fs. 3v y 4.

d) Joseph María del Barrio, Capitán, hijo del coronel Isidro del Barrio, de 24 años de edad, manifiesta igual parecer que los anteriores testimoniantes (Ibídem. fs. 4). En 1792, siendo Capitán de Milicias de Dragones, ocupa el cargo de Justicia Mayor del Partido de Huaylas, cuando era Sub Delegado Juan Garcés.

B. N. Sección manuscritos. C. 3636 (1792).

e) Domingo Gonzáles, español, de 38 años, estanciero y ganadero del pueblo de Huaraz, testimonia también en favor de los solicitantes respecto a la severidad de la sequía y epidemia que los asolaba. Legajo citado, fs. 5

f) Mariano Vergara, Teniente de Correo de 34 años, corrobora lo dicho por los testigos mencionados. Ibid., fs. $5 \mathrm{v}$.

Otorgó testamento y poder a favor de su hija Catalina Vergara el 12 de agosto de 1818. Fueron sus padres D. Pedro Vergara y Toro y doña Mariana Rubin de Celis. Casado con Margarita Nieto, tuvo como hijos a José Eusebio Vergara, quien fue Sub Teniente ya fallecido, y Catalina. A su vez su hijo José fue casado con Teresa Lostanau, teniendo como hijos a: Josefa, Juana, Leonor y Lorenzo Vergara Lostanau.

AGN, Escr. José Mendoza y Santa Cruz, 1818 (401), fol. 306v.

g) Joaquín Calvente, Alguacil Mayor de la provincia de 42 años de edad, llega a testimoniar sobre la condición de pauperismo a la que llegaron los lugareños a consecuencia de las inclemencias del tiempo. Legajo citado, fs. 6 y $6 \mathrm{v}$.

h) Norverto Macedo, comerciante de 74 años, manifiesta de manera idéntica respecto a las penurias por las cuales atravesaban los regnícolas. Ibídem. fs. 7 y $7 \mathrm{v}$.

${ }^{24}$ El vicario Herrera contesta la misiva del marqués el 14 de julio de 1780. Y añadiendo un comentario, expresa que "En una de las cláusulas antecedentes, dije que se pagaba un jornal de dos reales a los indios, y ahora he advertido que hay algunas haciendas en que solo se les paga un rreal, y este en unos efectos en que hagan un quinientos por ciento, después de bien oprobiados y castigados, lo que lloramos con lágrimas del corazón, sin poder remediar sus grandes usuras, con repetidas exortaciones que le hacemos a los que así roban los trabajos de los pobres. una firma (Herrera)".

Por su parte, Fernando de la Cámara, quien era vicario de Huaraz, Recuay y Marca por más de veinte años, contesta el pedido del marqués el 19 de julio de 1780 .

AGN. Leg. 35, fs. 9, 9v, 10v, 11 y $11 \mathrm{v}$. 
Manuel Enrique Valverde Gonzáles - Apuntaciones para la historia del derecho peruano. Un caso de política asistencial en favor de los partidos del corregimiento de Huaylas en el S. XVIII

quien en carta del 23 del mismo mes provee: "infórmese al señor juez de la Caja de Censos sobre la cantidad que tengan los pueblos de la provincia que se enuncia y pásese luego este expediente al señor fiscal"25. Empero, el 17 de octubre de aquel año, el juez de la Caja de Censos responde que el pago a la mencionada Caja estaba atrasado en varios años debido a los autos promovidos por el mismo marqués y que no había fondos para auxiliarlos, pues los que habían se remitieron a la Real Caja de Lima. En respuesta el corregidor, al dar una razón al pedido del fiscal sobre los bienes de los indígenas, decía que estos pobladores no tenían con qué pagar los tributos ${ }^{26}$, y que no había bienes de comunidades, salvo algunas manadas de ganado en la zona de Vertientes, los que no les redituaban ganancia alguna, más aún si es a raíz de la sequía se había visto notablemente mermada la ganadería en la zona.

Cabe anotar que los llamados rezagos eran los faltantes que no se entregaban totalmente en las fechas señaladas por la Real Hacienda y que muchas veces nunca se llegaban a rendir cuenta porque los curacas y gobernadores se ponían, de consuno, en componenda para entregar solo parte de las obvenciones faltantes; claro que en varias oportunidades sirvieron como base para la condena en los juicios de Residencia de estos funcionarios indianos.

Por esas fechas, junio de 1780, hizo el Marqués una visita de tasación a los pueblos de Vertientes (cadena montañosa occidental del Callejón de Huaylas, yuxtapuesta a la franja costera del actual departamento de Ancash), haciendo entrega de cabezas de ganado ovino de Castilla a determinados mayordomos por el lapso de un año a fin que con su crianza pudieran subsistir los indígenas del Callejón de Huaylas ${ }^{27}$.

Resulta interesante el comentario del Corregidor, al decir que los indígenas no se preocupaban mucho de la conservación y reproducción de su ganado, pues los curas doctrineros los despojaban de ellos por concepto de diezmos, punto que volveremos a tocar más adelante.

\footnotetext{
25 Ibid. fs. 14 .

${ }^{26} \mathrm{Ibid}$. fs. 16 y $16 \mathrm{v}$.

27 El Marqués realizó la entrega de 154 cabezas de ganado ovino, correspondiente de Santa María Magdalena de Pampas, y del pueblo de Marca 210 ovinos y 22 caprinos para lo cual nombró a los respectivos encargados por el plazo de un año como. Ibídem, fs. 20.

El P. Soriano Infante nos indica que el corregidor formó una razón circunstanciada de los bienes de comunidad que correspondían a las parcialidades y comunes de indios en 1781, expresando su anual importancia y del modo cómo se invertía y distribuía, visitando las manadas y hatos de toda la provincia. Cf. SORIANO INFANTE, A. «Rebeliones indígenas ...», p. 5.
} 
Manuel Enrique Valverde Gonzáles - Apuntaciones para la historia del derecho peruano. Un caso de política asistencial en favor de los partidos del corregimiento de Huaylas en el S. XVIII

Estando a los sucesos narrados, la gestión realizada por los curacas tuvo resultado favorable ya que el 13 de julio de 1780 José Ramos de Figueroa, Subdelegado de las Visitas y Superintendente de la Real Hacienda, ordena que se proceda al auxilio respectivo con 700 pesos cada año a contarse desde 1781. Previamente el Fiscal Juan José de Leuro expone que le “... parece muy de justicia y conforme a las piadosas intenciones de su Majestad contenidas en las leyes y ordenanzas del Reino que a los pueblos que los gozan, se les administre anualmente alguna proporcionada cantidad, para que prorrateada entre los contribuyentes de ellos puedan ser asi menos gravados en la contribución personal que hicieron: De este modo tendrían un debido cumplimiento las expresadas $R^{e s}$ decisiones y los indios [al] ver este auxilio y alivio, serán más puntuales en la satisfacción de sus tasas ..."28.

Para lograr el cobro de tal auxilio, las autoridades indígenas otorgan poder, con fecha 9 de junio de 1781, en San Sebastián de Huaraz, a Domingo Ramírez de Arellano para que haga efectivo el cobro de dicho apoyo económico ${ }^{29}$. Apoderado que cumple tal encomendación el 29 de julio de dicho año, pues recibió la orden librada por don Juan de Rivero y Peña ${ }^{30}$, Consejero de su Majestad y Oidor de la Real Audiencia, con lo que se concretiza el pago mediante decreto del 30 de julio de 1781.

Ante los insistentes requerimientos que se le hacían al marqués para que dé cuenta detallada de su corregimiento, contesta el 29 de agosto de 1781 a Juan de Rivero -quien en ese entonces era Juez Privativo del Juzgado Mayor de Censos de Comunidades de Indios-, que le era imposible dar dicha cuenta

\footnotetext{
${ }^{28}$ Ibid., fs. 22v y 23.

La actuación del Fiscal se ajustaba a lo dispuesto por la Ley XXII, Título IV, Libro VI de la Recopilación de Leyes de Indias de 1680, pues era el encargado de velar por los asuntos tocantes a los censos y bienes de comunidad, siendo su defensor y abogado en todo lo que fuere demandas, pedimentos, respuestas, excepciones y otros temas más, conforme se detalla en dicha ley.

${ }^{29}$ Ibid., fs. 24v, 25, 28v, 29 y $29 \mathrm{v}$.

Respecto a Domingo Ramírez de Arellano allegamos al lector algunos datos sobre su persona: Nació en La Rioja, fue ordenado Caballero de la Orden de Calatrava, además de ser Coronel de milicias y Capitán de la compañía de la guardia de Alabarderos en el gobierno del Caballero de Croix. Casó con Josefa Baquíjano y Carrillo. Fue dueño del navío "Mercedes" y Prior del Tribunal del Consulado entre 1793 y 1794. Falleció en junio de 1811. Mantuvo estrechos vínculos comerciales con el marqués de Casa Hermosa, pues ambos concertaban respecto a la venta de mulas en el Corregimiento de Huaylas. Por lo tanto, no hubiera sido extraño que ese apoderamiento otorgado por los curacas se haya dado a sugerencia del mismo corregidor. Para más pormenores se puede consultar a: AGUILAR GIL, Roisidia. «Domingo Ramírez de Arellano: Comerciante, naviero y hacendado». En: Los comerciantes limeños a fines del siglo XVIII. Capacidad y cohesión de una élite. 1750-1825. $3^{\mathrm{a}}$ ed. Lima: PUCP, 2000, pp. 175-185; MENDiburU. Op. Cit. T. IX, $2^{\mathrm{a}}$ ed., Lima: Librería e imprenta Gil, 1934, p. 290; RIZO-PATRÓN BOYLAN, Paul. Linaje, dote y poder. La nobleza de Lima de 1700 a 1850. Lima: PUCP, 2001, p. 114; VILLA EsTEVES, Deolinda Mercedes. «Una negociación de mulas en el corregimiento de Huaylas». En: Boletín del Instituto Riva Agüero. Lima, N 13, 1984-1985, pp. 379-393, y SWAYNE Y MENDOZA, Guillermo. Mis antepasados. Lima: Tipografía Peruana, 1951, pp. 266-270.

30 El historiador Guillermo Lohmann Villena lo identifica como Ramón de Ribera y Peña. Vid. Los ministros.., p. 118.
} 
Manuel Enrique Valverde Gonzáles - Apuntaciones para la historia del derecho peruano. Un caso de política asistencial en favor de los partidos del corregimiento de Huaylas en el S. XVIII

por los propios usos de los indios y que los diezmeros desempeñaban tales cargos por 60 u 80 años y pagaban por el pase de ellos 200 o 300 pesos y se les cobraba a golpes a los indios con la consecuente enervación del ganado, por lo que solicita se les prohíba a los curas los aludidos $\operatorname{cobros}^{31}$.

Como resultado de la contundente respuesta del marqués de Casa Hermosa, se le autoriza expresamente, con fecha 19 de octubre de 1783, a que tome las medidas necesarias "... previniéndole que si nota algún desorden en la administración de diezmos, lo represente separadamente donde corresponda..."32. Con esta carta no se hacía más que aplicar las leyes XXX a XXXI del Título V, Libro VI de la Recopilación de 1680, en donde se ordena que en cuanto al estipendio del doctrinero y los pagos a la iglesia se haga por separado de las recaudaciones propias de la corona.

Esta carta de respuesta da punto final al documento bajo estudio, por contener treinta y ocho fojas, que para efectos de nuestro comentario nos bastan para exponer un aspecto más de la política fiscal virreinal, y de paso de la historia ancashina, en una época en que también se cobijó un suceso de trascendental importancia para nuestra historia nacional como fue la revolución de Tupac Amaru II en el Cuzco.

\section{EXPRESIÓN JURÍDICA}

Desde la perspectiva jurídica, cabe remarcar lo relativo a las exoneraciones tributarias -puesto que estaban inafectos al pago de tributos los curacas, sus familiares y algunas otras personas expresamente indicadas en la copiosa legislación indiana-, las que estaban contempladas en el cuerpo legislativo vigente allende esos años, la Recopilación de las Leyes de Indias de 1680, la misma que, a tener lo dicho por el ilustre iushistoriador español José

\footnotetext{
${ }^{31}$ Si bien es cierto que el Diezmo era un impuesto en especie, controlado por la alta jerarquía eclesiástica, el diezmero era por lo general un laico a quien se le arrendaban periódicamente los cobros. (Legajo citado, fs. $34 \mathrm{v})$

Los clérigos en la primera década del S. XVII, para el caso de las órdenes, sus ingresos por sínodo o salario fueron de 122, 122 pesos de ocho reales en total, de 302 doctrinas que tenían en el virreinato del Perú. Posteriormente por el Concilio de Trento, se prefiere introducir como doctrineros a sacerdotes seculares que estaban más propensos a beneficiar a la corona y acatar el Regio Patronato. Pero en el S. XVIII, estos curas eran grandes propietarios y más bien se disputaban los tributos con la corona; habida cuenta que a fines de ese siglo se extinguieron los repartos y se hizo extensivo el diezmo a los indígenas -supresión por la que lucharon mucho los clérigos-, dando pie así para que se produzcan las denominadas revueltas anticlericales.

Cf. CASTAÑEDA, Paulino y Juan MARCHENA. «Las órdenes religiosas en América: propiedades, diezmos, excenciones y privilegios». En: Anuario de Estudios Americanos. T. XXXV. Sevilla, 1978, p. 30 de la separata especial, y O'PHELAN, S. «Revueltas anticlericales...», p. 134.

32 Leg. 35 fs. 37 y $37 \mathrm{v}$.
} 
Manuel Enrique Valverde Gonzáles - Apuntaciones para la historia del derecho peruano. Un caso de política asistencial en favor de los partidos del corregimiento de Huaylas en el S. XVIII

María Ots Capdequí, prescribía la conveniencia de moderar los tributos y de revisar las tasaciones cuando las circunstancias dadas así lo aconsejaban ${ }^{33}$. Para mejor detallar lo dicho, la Ley xlv, Título V, Libro VI de la mencionada Recopilación indicaba: "Que habiendo peste en pueblos de indios, se ordenen las tasas. Si los indios padecieran contagio de peste, mortandad es nuestra voluntad que sean relevados...".

Una argumentación mayor para apuntalar aún más las razones de las excepciones tributarias, la podemos hallar en la monumental Política Indiana, de Juan de Solórzano Pereyra, cuando precisa que: "La notoria pobreza también podrá escusar á los indios de la paga de estos tributos de que tratamos, como en los semejantes lo disponen algunos textos de derecho común y resuelven los glosadores"34, acotando a lo dicho, indica: "Pero si esta pobreza les sobreviniese á los indios por alguna grande esterilidad que aconteciese á los frutos y especies en que, ó en todo ó en parte, estuviesen tasados los tributos que han de pagar, más propensos deberíamos estar hacerles suelta o quiebra de ellos, como nos lo aconseja en una ley el jurisconsulto Ulpiano, y en otra los emperadores Arcadio y Onorio, concluyendo ambos, que esto lo pide la equidad y es justo lo concedan los príncipes y magistrados, pues no es razón de quien vé y llora perdido miserablemente su patrimonio, haya de tributar para engrosar el ageno..." 35 .

Pesada carga, era pues, el tributo que debían de soportar los indígenas, quienes además ya eran víctimas de grandes abusos cometidos por las autoridades coloniales, a las quese sumaban losclérigos quienes perseguían sus obvenciones respectivas, garramas que afrontaban los indígenas desde temprana edad exceptuándose a los curacas y sus hijos mayores, a la par que a sus mujeres, puesto que las veces que se trataron de incluir a los dichos curacas llegaron a producirse grandes perturbaciones debido a la ascendencia que tenían sobre sus gobernados, a pesar de que muchos de ellos eran los que cometían los mayores atropellos contra estos infelices oprimidos, aprovechándose de su nesciencia, para así exigirles más de lo debido, recurriendo para ello al uso de la mencionada duplicidad de padrones, punto que ya abordamos antes.

\footnotetext{
33 Cf. Ots CAPdeQuí, José María. Manual de historia del derecho español y del derecho propiamente indiano. $2^{\mathrm{a}}$ ed. Bs. As.: Ed. Losada S.A., 1945, pp. 252-53. Existe una primera edición a cargo del Instituto Ricardo Levene, Bs. As., 1943, en 2 vols. También se puede consultar una reelaboración de esta obra en su: Historia del derecho español en América y del derecho indiano. Madrid: Aguilar, 1969, pp. 211-213.

34 Cf. Solórzano Pereyra, Juan de. Política indiana. Madrid-Buenos Aires: Compañía Iberoamericana de Publicaciones, s/f. (¿1930?), corregida y aumentada por el Lic. Ramiro de Valenzuela, con prólogo de J. Mª . Ots Capdequí; t.1, Lib. II, Cap. XX, № 22 y ss. [Hay otra interesante edición en 3 tomos a cargo de Francisco Tomás y Valiente y Ana María Barrero, con prólogo del mismo F. Tomás y Valiente, Madrid, Fundación José Antonio de Castro, 1996.]

35 Ibid $\mathrm{N}^{\mathrm{o}} 27$.
} 
Manuel Enrique Valverde Gonzáles - Apuntaciones para la historia del derecho peruano. Un caso de política asistencial en favor de los partidos del corregimiento de Huaylas en el S. XVIII

La única forma de evitar pagar tal carga era mostrándose pobres, ocultando sus pertenencias, huyendo de sus comunidades, lo que al final de cuentas les traían más daños que el mismo pago de tributo, pues los "... caciques, escribe el gobernador Lope García de Castro, roban a los indios cuanto tienen; no hay esclavos que tan poca libertad tengan como estos pobres, y si por males de sus pecados algunos de ellos se queja de su cacique, luego desaparece que no se sabe más de él. Ninguno guarda tasa ni el indio osa quejarse" 36 .

Dábase el caso que los titulares, las más de las veces, eran obligados a tributar por los fallecidos, sin importarles el sufrimiento de sus familiares y acrecentando los resquemores ante tales prácticas extralimitadas, hecho que no es de extrañarse que también acontecía en el Corregimiento de Huaylas por encontrarse en una posición envidiable frente a sus similares, debido a que se le consideraba entre los corregimientos que más redituaban a las arcas del virreinato peruano, habida cuenta que por la compra del cargo de corregidor se pagaba por cabeza de cada población indígena un promedio de 2 a 4 pesos, como ocurrió en 1740; cifras que evidencian su ventajosa condición debiéndose ello, de seguro, a la ubérrima calidad de sus tierras, propicias para el cultivo de múltiples productos así como para el pastoreo durante todo el año, cuyos frutos que redundaban en provecho de sus exactores ${ }^{37}$.

Todos estos elementos hacían, en suma, que la situación de los indígenas se haga más oprobiosa, por lo que si a ello les avenía una epidemia de viruela como la que padecieron los lugareños provocaba un colapso poblacional que a la postre acrecentaría aún más las obligaciones tributarias de los súbditos, por tal razón es que los curacas de los pueblos del Callejón de Huaylas recurren ante la autoridad para poder ser asistidos con dineros que les permitieran solventar los gastos a los que estaban sometidos.

En lo atinente a la Caja de Censos y Bienes de Comunidad ${ }^{38}$, la legislación de la época regulaba los fines y modos de hacer uso de dichos fondos, cuya normatividad corría detallada en el Título IV, Libro VI de la citada Recopilación de 1680, siendo importante, para el caso que nos convoca, traer

${ }^{36}$ Citado por Villarán, Manuel Vicente. Apuntes sobre la realidad social de los indígenas del Perú ante las leyes de indias. Lima: s.p.i., 1964, p. 95.

37 Cf. GolTE, ob. cit., mapa N 16

38 Las Cajas de Comunidad de Indios fueron fundadas por el marqués de Cañete, quien dispuso que debían constituirse en todo pueblo o agrupación de indios, cuyos fondos se invertirían en el sostenimiento de sus hospitales, de sus bienes de pobres (en el auxilio de viudas, huérfanos, enfermos, inválidos, etc.), ayudar a sufragar los gastos de las misiones y demás elementos para la conversión, para permitirles efectuar sin detrimento de sus bienes el pago de tributos y en general para que sirviese de ayuda, socorro y alivio en sus necesidades. 
Manuel Enrique Valverde Gonzáles - Apuntaciones para la historia del derecho peruano. Un caso de política asistencial en favor de los partidos del corregimiento de Huaylas en el S. XVIII

a cita las leyes XIV y XX, referentes a que el dinero que resultare de los bienes, censos y rentas de la comunidad solamente se podía utilizar en el descanso y alivio de los indios, revirtiéndose en su provecho y utilidad, así como para gastar en sus necesidades para los que se fundaron dichos fondos ${ }^{39}$.

Resulta pertinente anotar que en los documentos oficiales no se hacen citas expresas a normas legales de la época para la concesión del auxilio económico, salvo en el caso del informe del Fiscal José de Leuro, quien menciona de manera genérica que las reales ordenanzas disponen que se les asista a los indígenas para que puedan pagar más adelante los tributos fijados por la corona. Cierto es que no era usual en esas épocas que se motivaran las resoluciones judiciales o decisiones administrativas, y menos que se estilara citar las normas legales que sustentaban las providencias de la judicatura o administración indiana. Empero, hemos colacionado algunas otras que nos permiten vislumbrar el sustento jurídico de la petición de los curacas que permitió se haga realidad el esperado auxilio de la Caja de Censos.

\section{COLOFÓN}

De todo lo expuesto, lo que se puede advertir respecto a este hecho, es que así como el régimen colonial español imponía una serie de gravámenes a la población indígena, también contemplaba, dentro de su intrincada y frondosa legislación, un procedimiento a través del cual se podía auxiliar a los regnícolas con determinadas cantidades de dinero para poder aliviar sus deprimida situación económica, lo cual no significa que este era un gesto de supuesta magnanimidad, pues a la larga lo único que se buscaba era garantizar el pago de los futuros impuestos, conforme se puede colegir del comentario del Fiscal Juan José de Leuro.

\footnotetext{
La gestión económica de las Cajas corría a cargo de los oficiales reales, nombrándose por cada Audiencia un administrador contador y pagador de las cajas de cada provincia, los cuales actuaban bajo el control y dirección del Juzgado de bienes de comunidad, integrado por el Oidor protector de indios, el Fiscal de la Audiencia, un escribano y un alguacil.

Para mayores datos sobre esta institución puede consultarse a: LAZO GARCíA, Carlos y Alex ORTEGAL IZQUIERDO. «La caja general de censos de indios de Lima, institución colonial de crédito dinerario (Perú 1580-1821)». En: Fénix. Revista de la Biblioteca Nacional del Perú. №39. Lima, 1997, p. 95 y ss., así como ViÑAS MeY, Carmelo. El régimen jurídico y la responsabilidad en la América indiana. Proemio de Antonio Martínez Báez. 2a ed. México: UNAM, 1993, p. 32, y MORENO CEBRIÁN. El corregidor de indios..., p. 243 y ss.

39 En el año 1777 el Real Tribunal del Consulado hace un préstamo a la corona por un monto de un millón y medio de pesos, para ser utilizados en la expedición de Buenos Aires.

Por otro lado el mismo Tribunal consular sugiere que se tomen los fondos existentes en la Caja de Censos por el monto de 48000 pesos, a 3\% de interés anual, objetivo que se logró al contar con la autorización de los fiscales, el Juez privativo y defensor de naturales, además del Acuerdo de la Real Audiencia. Cf. AGN, Superior Gobierno, Leg. 16, c. 407, 1777.
} 
Manuel Enrique Valverde Gonzáles - Apuntaciones para la historia del derecho peruano. Un caso de política asistencial en favor de los partidos del corregimiento de Huaylas en el S. XVIII

El entramado legal que tenía la corona en el nuevo mundo se muestra de manera patente en este caso analizado, pues no solamente nos permite desplazarnos a través de las manifestaciones sociales sino que, para el campo jurídico que nos interesa particularmente, se evidencia que las mismas autoridades locales recurren al uso de mecanismos legales pertinentes para lograr un apoyo económico a favor de sus pueblos, lo cual no obsta para dejar en claro que en todo este procedimiento se contó con la participación de activos personajes de la colonia, siendo uno de ellos Domingo Ramírez de Arellano, quien era un asiduo comerciante de mulas en dicho corregimiento debido a sus estrechas relaciones comerciales con el susodicho marqués, además de tener una posición social relevante a causa de sus vinculaciones familiares nacidas de su matrimonio con doña Josefa Baquíjano y Carrillo.

Por otra parte, no hemos podido determinar cuál era el procedimiento que se seguía en este tipo de casos, tanto por la ausencia de regulación normativa expresa en la legislación colonial como de casos similares, razón por la cual nos hemos limitado a describir el iter procedimental seguido, realizando algunas apuntaciones de orden jurídico basándonos en las fuentes doctrinarias de la época.

Relevante también resulta anotar que en todo el documento histórico bajo estudio no se haga una sola referencia a las trapatiestas mencionadas por nuestra parte, y tanto las autoridades locales como las de la sede virreinal solo se hayan limitado a considerar los apremios económicos de los lugareños, pese a estar íntimamente entrelazados los hechos.

Finalmente, por lo menos para este caso en concreto, se observa que la Caja de censos de Indios cumplió con su finalidad para la cual se creó, cual fue el de auxiliar a los indígenas en casos de necesidad ${ }^{40}$.

${ }^{40}$ Queremos expresar nuestro agradecimiento al ilustre historiador huaracino D. Manuel Reina Loli, quien generosamente nos permitió acceder a su archivo de revistas de la región y a sus propias obras sobre las revueltas en el callejón de Huaylas, que de otro modo no nos hubiese sido posible consultarlas, carencia que habría hecho aún más este sencillo trabajo. 